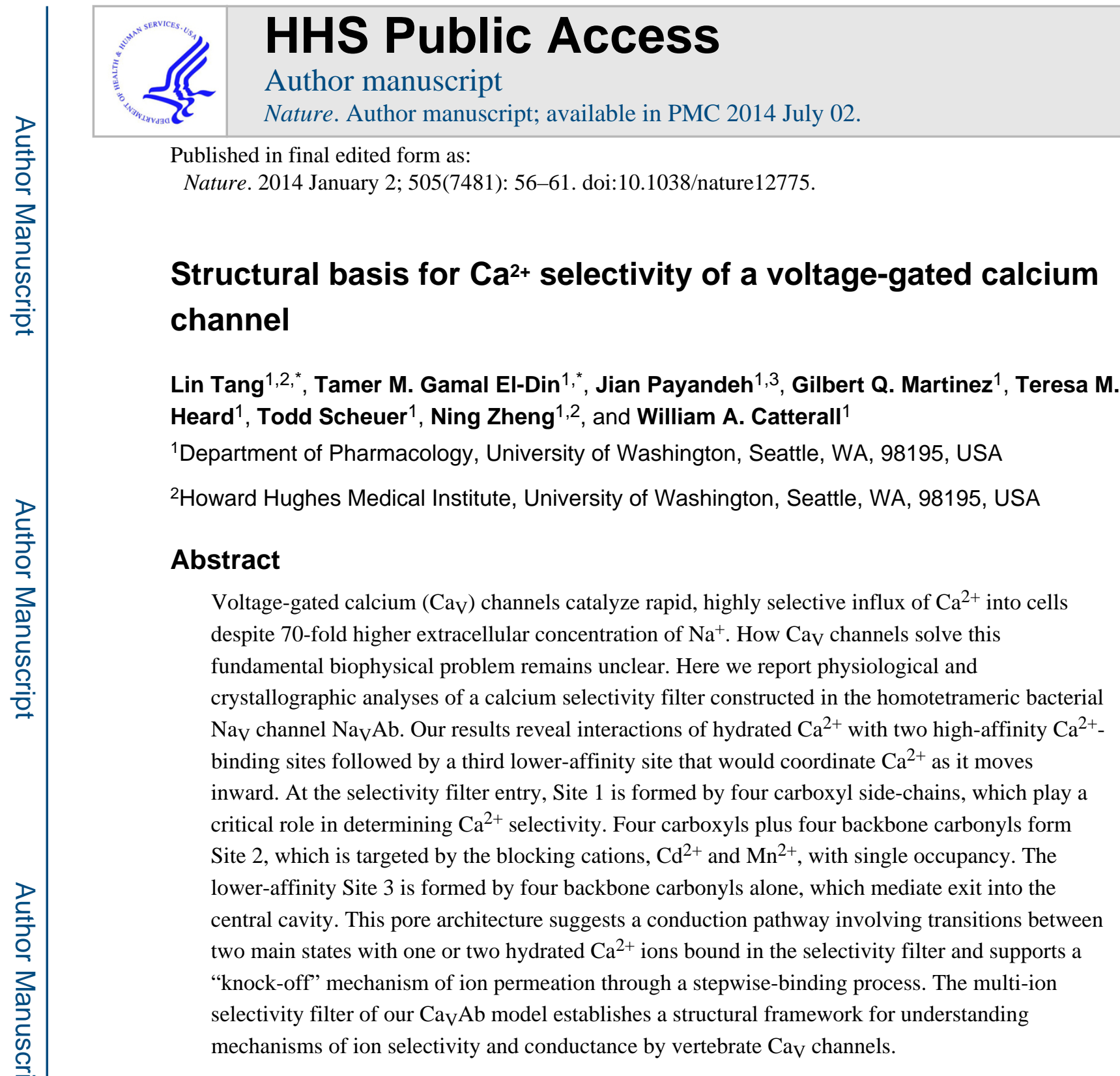

Users may view, print, copy, download and text and data- mine the content in such documents, for the purposes of academic research, subject always to the full Conditions of use: http://www.nature.com/authors/editorial_policies/license.html\#terms

Correspondence and requests for materials should be addressed to N.Z. (nzheng@uw.edu) and W.A.C. (wcatt@uw.edu).

${ }^{3}$ Present address: Department of Structural Biology, Genentech Inc., South San Francisco, CA, 94080, USA

* These authors contributed equally to this work

Author contributions

L.T., T.M.G.D., J.P., T.S., N.Z., and W.A.C. designed the experiments. J.P. initiated the experimental work. L.T. conducted the protein purification, crystallization, and diffraction experiments. L.T., J.P., and N.Z. determined and analyzed the structures of the apo and cation bound forms of CaVAb and the intermediate CaVAb constructs. T.M.G.D. and T.S. performed physiological studies of CavAb and related constructs. G.M. and T.M.H made the constructs and performed the preliminary data collection. All authors interpreted the structures in light of the physiological data. L.T., N.Z., and W.A.C. wrote the manuscript with input from all coauthors. W. A. C. and N. Z. are co-senior authors.

Coordinates and structure factors have been deposited in the Protein Data Bank under accession codes: 4MS2 (TLDDWSN, 15 mM $\mathrm{Ca}^{2+}$ ), 4MTF(TLDDWSN, $0.5 \mathrm{mM} \mathrm{Ca}^{2+}$ ), 4MTG (TLDDWSN, $2.5 \mathrm{mM} \mathrm{Ca}^{2+}$ ), 4MTO (TLDDWSN, $5 \mathrm{mM} \mathrm{Ca}^{2+}$ ), 4MVM (TLDDWSN, $10 \mathrm{mM} \mathrm{Ca}^{2+}$ ), 4MVO (TLDDWSN, $15 \mathrm{mM} \mathrm{Ca}^{2+}$ ), 4MVQ (TLDDWSD, $15 \mathrm{mM} \mathrm{Ca}^{2+}$ ), 4MVR (TLDDWSD, 100 $\mathrm{mM} \mathrm{Mn}^{2+}$ ), 4MVS (TLDDWSD, $100 \mathrm{mM} \mathrm{Cd}^{2+}$ ), 4MVZ (TLEDWSD, $15 \mathrm{mM} \mathrm{Ca}^{2+}$ ), 4MW3 (TLDDWSM, $15 \mathrm{mM} \mathrm{Ca}{ }^{2+}$ ), $4 \mathrm{MVU}$ (TLEDWSM, $15 \mathrm{mM} \mathrm{Ca}^{2+}$ ), $4 \mathrm{MW} 8$ (NavAb, $15 \mathrm{mM} \mathrm{Ca}^{2+}$ ).

The authors declare no competing financial interests. 
$\mathrm{Ca}^{2+}$ ions flow through voltage-gated $\mathrm{Ca}^{2+}\left(\mathrm{Ca}\right.$ ) channels at a rate of $\sim 10^{6}$ ions/s, yet $\mathrm{Na}^{+}$ conductance is $>500$-fold lower ${ }^{1}$. Such high-fidelity, high-throughput $\mathrm{Ca}_{V}$ channel performance is important to regulate intracellular processes such as contraction, secretion, neurotransmission, and gene expression in many different cell types ${ }^{2}$. Because the extracellular concentration of $\mathrm{Na}^{+}$is 70 -fold higher than $\mathrm{Ca}^{2+}$, these essential biological functions require $\mathrm{Ca} V$ channels to be highly selective for $\mathrm{Ca}^{2+}$ in preference to $\mathrm{Na}^{+}$, even though $\mathrm{Ca}^{2+}$ and $\mathrm{Na}^{+}$have nearly identical diameter $(\sim 2 \AA)$. Ion selectivity of $\mathrm{Ca}_{\mathrm{V}}$ channels is proposed to result from high-affinity binding of $\mathrm{Ca}^{2+}$, which prevents $\mathrm{Na}^{+}$permeation. Fast $\mathrm{Ca}^{2+}$ flux through $\mathrm{Ca}_{\mathrm{V}}$ channels is thought to utilize a 'knock-off' mechanism in which electrostatic repulsion between $\mathrm{Ca}^{2+}$ ions within the selectivity filter overcomes tight binding of a single $\mathrm{Ca}^{2+}$ ion $^{1,3-8}$. Most of these mechanisms require a multi-ion pore, yet extensive mutational analyses of ion selectivity and cation block of vertebrate $\mathrm{Ca}_{V}$ channels support a single high-affinity $\mathrm{Ca}^{2+}$ binding site ${ }^{1,9-14}$.

$\mathrm{Ca}_{\mathrm{V}}$ channels contain a single ion-selective pore in the center of four homologous domains ${ }^{2}$. The central pore is lined by the S5 and S6 transmembrane helices and the intervening " $\mathrm{P}$ loop" from each domain in a four-fold pseudosymmetric arrangement. The four voltagesensing modules composed of S1-S4 transmembrane helices are symmetrically arranged around the central pore. $\mathrm{Ca}_{\mathrm{V}}$ channels are members of the voltage-gated ion channel superfamily and are closely related to voltage-gated $\mathrm{Na}^{+}\left(\mathrm{Na}_{\mathrm{V}}\right)$ channels. The structures of three homotetrameric bacterial $\mathrm{Na}_{\mathrm{V}}$ channels open the way to elucidating the structural basis for ion selectivity and conductance of vertebrate $\mathrm{Na}_{\mathrm{V}}$ and $\mathrm{Ca}_{\mathrm{V}}$ channels ${ }^{15-17}$, which likely evolved from the bacterial $\mathrm{NaChBac}$ family and retained similar structures and functions (Supplementary Fig. 1) ${ }^{18-20}$. Interestingly, mutation of three amino acid residues in the selectivity filter of $\mathrm{NaChBac}$ is sufficient to confer $\mathrm{Ca}^{2+}$ selectivity ${ }^{21}$. We have introduced analogous mutations into the bacterial $\mathrm{Na}_{\mathrm{V}}$ channel $\mathrm{Na}_{\mathrm{V}} \mathrm{Ab}$ to create $\mathrm{Ca}_{\mathrm{V}} \mathrm{Ab}$ and carried out electrophysiological and $\mathrm{X}$-ray crystallographic analyses to determine the relative permeability of $\mathrm{Ca}^{2+}$ and define ion-binding sites in the selectivity filter. Our systematic analyses of $\mathrm{Ca}_{\mathrm{V}} \mathrm{Ab}$ and intermediate derivatives provide structural and mechanistic insights into $\mathrm{Ca}^{2+}$ binding and ion permeation and suggest a conductance mechanism involving two energetically similar ion occupancy states with one or two hydrated $\mathrm{Ca}^{2+}$ ions bound.

\section{Structure and function of $\mathrm{Ca}_{\mathrm{v}} \mathrm{Ab}$}

$\mathrm{Na}_{\mathrm{V}} \mathrm{Ab}$ channels have four identical pore motifs $\left({ }^{175} \mathrm{TLESWSM}^{181}\right)$ that form the ion selectivity filter ${ }^{15}$. The side chains of E177 form a high-field-strength site (Site $\mathrm{HFS}_{\text {) }}$ ) at the outer end of the filter, while two additional potential $\mathrm{Na}^{+}$coordination sites, Site $_{\mathrm{CEN}}$ and Site $_{\mathrm{IN}}$, are formed by the backbone carbonyls of L176 and T175 ${ }^{15}$. To create CaVAb, E177, S178, and M181 were substituted with Asp, resulting in a mutant with the pore motif ${ }^{175}$ TLDDWSD ${ }^{181}$ (underlined letters indicate mutated residues). $\mathrm{Ca}_{\mathrm{V}} \mathrm{Ab}$ was expressed in Trichopulsia $\mathrm{ni}$ cells (Hi5) and analyzed by whole-cell voltage clamp to determine its ion selectivity. In contrast to $\mathrm{Na}_{\mathrm{V}} \mathrm{Ab}$, which does not conduct extracellular $\mathrm{Ca}^{2+}$ ions but carries outward $\mathrm{Na}^{+}$current (Fig. 1a, b), $\mathrm{Ca}$ Ab conducts inward $\mathrm{Ca}^{2+}$ current in a voltage-dependent manner (Fig. 1c, d). Complete titration curves for $\mathrm{Ca}^{2+}$ in the presence of $\mathrm{Ba}^{2+}$ as the balancing divalent cation (see Methods) revealed inhibition of $\mathrm{Ba}^{2+}$ current by low concentrations of $\mathrm{Ca}^{2+}$ followed by increases in $\mathrm{Ca}^{2+}$ current at higher $\mathrm{Ca}^{2+}$ 
concentrations (Fig. 1e). These results demonstrate the anomalous mole fraction effect characteristic of vertebrate $\mathrm{Ca} V$ channels. Comparable experiments with $\mathrm{Na}^{+}$as the balancing cation were not possible because of the instability of the Hi5 cells in solutions with low divalent cation concentrations. The reversal potential for $\mathrm{Ca}^{2+}$ current under biionic conditions closely follows the expectation for a highly $\mathrm{Ca}^{2+}$-selective conductance (30.6 $\pm 2.3 \mathrm{mV} /$ decade, Fig. 1f; Supplementary Fig. 2), and $\mathrm{Ca}_{\mathrm{V}} \mathrm{Ab}$ selects $\mathrm{Ca}^{2+} 382$-fold over $\mathrm{Na}^{+}$under our standard recording conditions, yielding $>10,000$-fold $\mathrm{P}_{\mathrm{Ca}}: \mathrm{P}_{\mathrm{Na}}$ range for these constructs (Fig. 1g). Intermediate $\mathrm{Ca}_{\mathrm{V}} \mathrm{Ab}$ derivatives with single and double Asp substitutions had progressive increases in $\mathrm{Ca}^{2+}$ selectivity (Fig. 1g; Supplementary Fig. 2), as observed for $\mathrm{NaChBac}^{21}$. The ${ }^{175}$ TLDDWS $\underline{N}^{181}$ mutant has an Asn residue in place of the final Asp, as observed in one domain of mammalian $\mathrm{Ca}_{\mathrm{V}}$ channels (Supplementary Fig. 1), and it still favors $\mathrm{Ca}^{2+}$ over $\mathrm{Na}^{+}$by more than 100 -fold (Fig. $1 \mathrm{~g}$ ).

We have crystallized and determined the structure of $\mathrm{Ca}_{V} \mathrm{Ab}$ and its derivatives by molecular replacement using the $\mathrm{Na}_{\mathrm{V}} \mathrm{Ab}$ structure (PDB code 3RVY) as the search template (Supplementary Table 1). The overall structure of $\mathrm{Ca}_{\mathrm{V}} \mathrm{Ab}$ is very similar to that of $\mathrm{Na}_{\mathrm{V}} \mathrm{Ab}$, with an RMSD of $0.4 \AA$ (Fig. 1h). However, the electrostatic potential at the outer entry to the selectivity filter is more negative for $\mathrm{Ca}_{V} \mathrm{Ab}$ than for $\mathrm{Na}_{\mathrm{V}} \mathrm{Ab}$ (Supplementary Fig. 3). The three negatively charged Asp residues introduced at the selectivity filter of $\mathrm{Ca}_{\mathrm{V}} \mathrm{Ab}$ create a wide, short, electronegatively lined pore ( 6 A diameter, 10 A length) with no significant alteration in backbone structure with respect to $\mathrm{Na}_{\mathrm{V}} \mathrm{Ab}$ (Fig. 1i, j, Supplementary Fig. 4). Thus, $\mathrm{Ca}^{2+}$ selectivity of $\mathrm{Ca}_{\mathrm{V}} \mathrm{Ab}$ is mainly determined by the side chains of the amino acids at the selectivity filter.

\section{$\mathrm{Ca}^{2+-b i n d i n g ~ s i t e s ~ i n ~ t h e ~ p e r m e a t i o n ~ p a t h w a y ~}$}

The $3.2 \AA$ resolution structure of the mutant ${ }^{175}$ TLDDWS $\underline{N}^{181}$ in the presence of $10 \mathrm{mM}$ $\mathrm{Ca}^{2+}$ reveals electron densities in the selectivity filter consistent with three $\mathrm{Ca}^{2+}$ ions aligned on the central axis (Fig. 2a). In the outer vestibule leading to the selectivity filter, there are two additional less-intense on-axis peaks associated with weaker surrounding densities. To confirm the identity of the bound ions, we collected X-ray diffraction data at $1.75 \AA$ wavelength and calculated the $\mathrm{F}^{+}{ }_{\mathrm{ca}}-\mathrm{F}^{-}{ }_{\mathrm{ca}}$ anomalous difference map. Two strong peaks followed by a weaker peak on the intracellular side were found in the selectivity filter along the ion-conduction pathway, verifying three binding sites for $\mathrm{Ca}^{2+}$ (Fig. 2b). We name these Site 1, Site 2, and Site 3 from the extracellular to the intracellular side.

The $\mathrm{Ca}^{2+}$ ion at Site 1 is predominantly coordinated by the carboxyl groups of D178 (Site $\mathrm{EX}$ in $\mathrm{Na}_{\mathrm{V}} \mathrm{Ab}$ ), which define a plane at the selectivity filter entrance on the extracellular side of the bound $\mathrm{Ca}^{2+}$ ion (Fig. 2b). The distance between the carboxyl oxygen and $\mathrm{Ca}^{2+}$ is about 4.0 $\AA$. This distance suggests that the ion binds at this site in a hydrated form because the ionic diameter of $\mathrm{Ca}^{2+}$ is $2.28 \AA$, too small to interact with the carboxylate anions directly but appropriate for interaction through bound water molecules. Further into the pore, the four acidic side chains of D177 ( Site $_{\mathrm{HFS}}$ in $\mathrm{Na}_{\mathrm{V}} \mathrm{Ab}$ ) are located along the wall of the selectivity filter rather than projecting into the lumen, thereby also allowing the binding of a fully hydrated $\mathrm{Ca}^{2+}$ ion (Fig. 2b). Different from Site 1, this central $\mathrm{Ca}^{2+}$ binding site (Site

2 ) is surrounded by a box of 4 carboxylate oxygen atoms from D177 above and 4 backbone 
carbonyl oxygen atoms from $\mathrm{L} 176$ below ( Site $_{\mathrm{CEN}}$ in $\mathrm{Na}_{\mathrm{V}} \mathrm{Ab}$ ), with oxygen-Ca ${ }^{2+}$ distances of $4.5 \AA$ and $4.2 \AA$, respectively (Fig. $2 b$ ). At the intracellular side of the pore, the third $\mathrm{Ca}^{2+}$ binding site (Site 3 ) is composed of one plane of four carbonyls from T175 (Site IN $_{\text {in }}$ $\mathrm{Na}_{V} \mathrm{Ab}$ ), which point inward to the lumen (Fig. 2b). Here the $\mathrm{Ca}^{2+}$ ion lies nearly on the same plane as T175 carbonyls. The chemical environment of Site 3 hints at a lower affinity, consistent with its role in exit of $\mathrm{Ca}^{2+}$ from the selectivity filter into the central cavity. Throughout the selectivity filter, the oxygen- $\mathrm{Ca}^{2+}$ coordination distances are in the range of 4.0 - $5.0 \AA$, suggesting that the bound $\mathrm{Ca}^{2+}$ ion is continuously stabilized in a fully hydrated state when it passes through the pore. We observed diffuse electron density and in favorable cases discrete water molecules surrounding the bound $\mathrm{Ca}^{2+}$, consistent with the presence of an inner shell of bound waters of hydration (Supplementary Fig. 5).

Although the anomalous difference map did not resolve clear peaks at the outer vestibule beyond the selectivity filter, we interpret the two on-axis $2 \mathrm{~F}_{\mathrm{o}}-\mathrm{F}_{\mathrm{c}}$ densities above the three $\mathrm{Ca}^{2+}$ sites as two additional $\mathrm{Ca}^{2+}$ ions poised to enter the pore (Fig. 2a). This assignment is supported by the surrounding eight islets of density, which likely represent eight stabilized water molecules. Just as at Site 2 in the selectivity filter, these eight water molecules appear to serve as a square antiprism cage coordinating a hydrated $\mathrm{Ca}^{2+}$ ion at the center (Fig. 2a). The second $\mathrm{Ca}^{2+}$ ion located at the bottom of this cage is $\sim 4.5 \AA$ away from the four carboxyl oxygen atoms of D178, suggesting that part of its second hydration shell is replaced by D178 before the ion enters the selectivity filter. The selectivity filter, therefore, appears to select $\mathrm{Ca}^{2+}$ at its mouth by recognizing the $\mathrm{Ca}^{2+}$-hydration complex and conduct $\mathrm{Ca}^{2+}$ by fitting the $\mathrm{Ca}^{2+}$-hydration complex into the pore. Because $\mathrm{Ca}^{2+}$ is more electropositive than $\mathrm{Na}^{+}$, it should bind more tightly in the ion selectivity filter of $\mathrm{Ca}_{V} \mathrm{Ab}$, providing a mechanistic basis for the block of $\mathrm{Na}^{+}$permeation by $\mathrm{Ca}^{2+}$ at low $\mathrm{Ca}^{2+}$ concentration and preferential permeation of $\mathrm{Ca}^{2+}$ at higher $\mathrm{Ca}^{2+}$ concentration (Supplementary Discussion).

\section{Functional roles of key selectivity filter residues}

Measurements of bi-ionic reversal potentials revealed that the relative permeability of different $\mathrm{Ca}_{\mathrm{V}} \mathrm{Ab}$ intermediate constructs for $\mathrm{Ca}^{2+}$ follows the order of $\mathrm{CavAb}$ $\left({ }^{175} \mathrm{TLDDWS}^{181}\right)>\underline{1}^{175} \mathrm{TLDDWSN}^{181}>{ }^{175} \mathrm{TLEDWS}^{181}>{ }^{175} \mathrm{TLEDWSM}^{181}>\mathrm{Na}_{V} \mathrm{Ab}$ $\left({ }^{175}\right.$ TLESWSM $^{181}$ ) $>{ }^{175}$ TLDSWSM ${ }^{181}$ (Fig. 1g; Supplementary Fig. 2). A comparison of the $\mathrm{Ca}^{2+}$ selectivity ratios between ${ }^{175}{ }^{\text {TLEDWSM }}{ }^{181}$ and ${ }^{175}$ TLESWSM $^{181}\left(\mathrm{Na}_{\mathrm{V}} \mathrm{Ab}\right)$ shows that substitution of $\mathrm{S} 178$ with Asp is sufficient to convert the selectivity from $\mathrm{Na}^{+}$to $\mathrm{Ca}^{2+}$ with >100-fold change in $\mathrm{P}_{\mathrm{Ca}}: \mathrm{P}_{\mathrm{Na}}$ (Fig. 1g). Placement of the Asp carboxyl side chain at this position allows formation of the first hydrated $\mathrm{Ca}^{2+}$ binding site in the selectivity filter (Fig. 2c; Supplementary Fig. 6). By contrast, $\mathrm{S} 178$ in NavAb binds $\mathrm{Ca}^{2+}$ directly by displacing its hydration shell, which blocks conductance of both $\mathrm{Na}^{+}$and $\mathrm{Ca}^{2+}$ (Fig. 2d). Therefore, formation of Site 1 for binding hydrated $\mathrm{Ca}^{2+}$ is both necessary and sufficient for conferring $\mathrm{Ca}^{2+}$ selectivity over $\mathrm{Na}^{+}$to $\mathrm{Na} V \mathrm{Ab}$.

The $\mathrm{Ca}^{2+}$ selectivity ratio of $\mathrm{Ca}_{\mathrm{V}} \mathrm{Ab}\left({ }^{175} \mathrm{TLDDWSD}^{181}\right)$ is 5.5 -fold higher than ${ }^{175}$ TLEDWSD ${ }^{181}$ (Fig. 1g). This functional difference reflects a role of Site 2 in adjusting $\mathrm{Ca}^{2+}$ selectivity. Different from the side chains of D177 in $\mathrm{Ca}_{\mathrm{V}} \mathrm{Ab}$ 
$\left({ }^{175}\right.$ TLDDWS $\underline{D}^{181}$ ), which interact with the $\mathrm{Ca}^{2+}$ ion (Fig. 2e), the carboxyl group of E177 in ${ }^{175}$ TLEDWS $\underline{D}^{181}$ swings away from the selectivity filter and forms a hydrogen bond with D181 and the main-chain nitrogen atoms of S180 (Fig. 2f, Supplementary Fig. 7). Site 2 in ${ }^{175}$ TLEDWSD ${ }^{181}$, therefore, is exclusively formed by the four carbonyl oxygen atoms of L176, which conceivably leads to a lower $\mathrm{Ca}^{2+}$ binding affinity and a decreased $\mathrm{Ca}^{2+}$ selectivity. This comparison highlights both the importance of Site 2 in supporting high $\mathrm{Ca}^{2+}$ selectivity and the critical role of the backbone carbonyl groups of L176 in constructing this ion-binding site.

Distinct from D177 and D178, the N181 residue of ${ }^{175}$ TLDDWSN $^{181}$ lies outside the ionconducting pore and is not directly involved in $\mathrm{Ca}^{2+}$ ion coordination. In close proximity to the carboxyl groups of D178, which form a ring that lines the perimeter of the pore entryway, the side chain of N181 embraces the perimeter of the D178 ring by donating a hydrogen bond to its side chain carboxyls (Fig. 3a). Such a structural arrangement is also found in $\mathrm{Ca}_{\mathrm{V}} \mathrm{Ab}\left({ }^{175} \mathrm{TLDDWSD}{ }^{181}\right)$ (Fig. 3b), although the more electronegative environment created by the extra negatively charge residue, D181, likely attracts $\mathrm{Ca}^{2+}$ more strongly and confers a 4- to 5-fold higher degree of $\mathrm{Ca}^{2+}$ selectivity to $\mathrm{Ca}$ Ab $\left({ }^{175} \mathrm{TLDDW} \underline{S D}^{181}\right)$ in comparison to ${ }^{175} \mathrm{TLDDWSN}^{181}$ (Fig. 1g and Supplementary Fig. 3).

${ }^{175}$ TLDDWSM $^{181}$, which has the hydrophobic residue M181 packed next to the D178 ring, is the only $\mathrm{Ca}_{V} \mathrm{Ab}$ intermediate that does not conduct $\mathrm{Ca}^{2+}$ (Supplementary Fig. 2). The crystal structure of this mutant reveals a blocking $\mathrm{Ca}^{2+}$ ion tightly bound at Site 1 in a dehydrated state with an oxygen-ion distance of $2.3 \AA$ (Fig. 3c). Superposition analysis shows few structural differences between ${ }^{175}$ TLDDWSM $^{181}$ and ${ }^{175}$ TLDDWSN $^{181}$, except for the side chain of D178, which is fixed by N181 in ${ }^{175}$ TLDDWSN but unconstrained in ${ }^{175}$ TLDDWSM $^{181}$ (Fig. 3a, c). This comparison indicates that N181 in ${ }^{175}$ TLDDWS $\underline{N}^{181}$ and D181 in $\mathrm{Ca}_{\mathrm{V}} \mathrm{Ab}$ play a critical role in engaging D178 and allowing the reversible binding of the $\mathrm{Ca}^{2+}-\mathrm{H}_{2} \mathrm{O}$ hydration complex for active $\mathrm{Ca}^{2+}$ conductance. Although the subtle difference in $\mathrm{Ca}^{2+}$ selectivity between ${ }^{175}$ TLEDWSD ${ }^{181}$ and ${ }^{175}$ TLEDWSM $^{181}$ seems to argue against this conclusion (Fig. 1g), E177 in ${ }^{175}$ TLEDWSM ${ }^{181}$ actually plays a structural role equivalent to that of N181 in ${ }^{175}$ TLDDWSN ${ }^{181}$ — by pointing away from the selectivity filter lumen, E177 forms a carboxylate-carboxylate pair with D178 and holds it in a conduction-competent position (Fig. 3d, Supplementary Fig. 8).

\section{Block of $\mathrm{Na}_{\mathrm{v}} \mathrm{Ab}$ and $\mathrm{Ca} \mathrm{v}_{\mathrm{v}} \mathrm{Ab}$ channels by divalent cations}

$\mathrm{Cd}^{2+}, \mathrm{Mn}^{2+}$ and other inorganic cations are effective blockers of $\mathrm{Ca}_{\mathrm{V}}$ channels ${ }^{1}$. Block of $\mathrm{Ca}^{2+}$ conductance of $\mathrm{Ca}_{\mathrm{V}} \mathrm{Ab}$ by $\mathrm{Cd}^{2+}$ and $\mathrm{Mn}^{2+}$ gives $\mathrm{K}_{\mathrm{i}}$ values of $1.78 \mu \mathrm{M}$ for $\mathrm{Cd}^{2+}$ and $526 \mu \mathrm{M}$ for $\mathrm{Mn}^{2+}$ (Fig. 3e, f, blue). $\mathrm{Cd}^{2+}$ has lower affinity and $\mathrm{Mn}^{2+}$ has higher affinity for block of ${ }^{175}$ TLDDWSN ${ }^{181}$ (Fig. 3e, f, red). Crystals with bound $\mathrm{Cd}^{2+}$ and $\mathrm{Mn}^{2+}$ were obtained by soaking $\mathrm{Ca}_{\mathrm{V}} \mathrm{Ab}$ crystals in a cryo-solution containing these heavy metal ions, and the anomalous difference map was calculated from a dataset collected at $1.75 \AA$ wavelength. The structures show that both $\mathrm{Cd}^{2+}$ and $\mathrm{Mn}^{2+}$ bind in the selectivity filter at the central site (Site 2), which is coordinated by the side chains of the four D177 residues and the carbonyl groups of L176 (Fig. 3g, h). Locked at this site, these blocking ions would inhibit the $\mathrm{Ca}^{2+}$ current by competitively binding to the high affinity site required for $\mathrm{Ca}^{2+}$ 
permeation. Another important common feature of the two blocking complexes of $\mathrm{Ca}_{\mathrm{V}} \mathrm{Ab}$ is the block of permeation by binding of a single divalent cation within the selectivity filter, which supports the hypothesis that at least two divalent cation binding sites must be located close enough to induce repulsive interactions and allow divalent cation conductance by a knock-off mechanism. Because they are smaller than $\mathrm{Ca}^{2+}$, the bound $\mathrm{Cd}^{2+}(\mathrm{d}=2.18 \AA)$ and $\mathrm{Mn}^{2+}(\mathrm{d}=1.94 \AA)$ must interact with the selectivity filter through bound waters of hydration, and electron density consistent with bound waters of hydration is observed in our structures (Supplementary Fig. 5).

\section{Ion binding at the $\mathrm{Ca}^{2+}$ selectivity filter}

To assess the properties of the three $\mathrm{Ca}^{2+}$ binding sites in the selectivity filter of ${ }^{175}$ TLDDWSN $\underline{N}^{181}$, we titrated the concentration of $\mathrm{Ca}^{2+}$ in the cryo-solution and calculated the anomalous difference maps. At low $\mathrm{Ca}^{2+}$ concentration, two strong peaks of approximately equal intensity are found at Site 1 and Site 2 (Supplementary Fig. 9). As the $\mathrm{Ca}^{2+}$ concentration is raised, the electron density of Site 2 is substantially enhanced, but the peak intensity is reduced at Site 1 and remains low at Site 3 (Supplementary Fig. 9). These results imply that the central site has the highest affinity, whereas Site 3 is the weakest. It is likely that this titration pattern reflects independent binding of $\mathrm{Ca}^{2+}$ to Sites 1, 2, and 3 located in different individual molecules of $\mathrm{Ca}_{\mathrm{V}} \mathrm{Ab}$ at low $\mathrm{Ca}^{2+}$ concentration, whereas increasing concentrations of $\mathrm{Ca}^{2+}$ saturate Site 2 in most or all individual $\mathrm{Ca}_{\mathrm{V}} \mathrm{Ab}$ molecules and reduce or eliminate binding at Sites 1 and 3 by repulsion. Importantly, the two flanking sites have lower affinity than the central site, as proposed in the "stepwise binding model" of $\mathrm{Ca}_{\mathrm{V}}$ channel permeation ${ }^{7}$. In this model, the presence of flanking sites of intermediate affinity facilitates the movement of $\mathrm{Ca}^{2+}$ into and out of a central high-affinity site, which can result in high ion conductance, even in the limiting case where there is no repulsion between bound ions.

Consistent with a high binding affinity, $\mathrm{Ca}^{2+}$ binds at Site 2 with its first hydration shell waters coordinated with eight oxygen atoms from the channel (Fig. 2b, Supplementary Fig. 5). In contrast, $\mathrm{Ca}^{2+}$ at Site 1 is mainly stabilized by one plane of four carboxyl groups from D178. The distance between the $\mathrm{Ca}^{2+}$ ion at Site 1 and the carboxyl group of D177 at Site 2 is about $5.5 \AA-6 \AA$. As the $\mathrm{Ca}^{2+}$ ion moves inward, this distance will be reduced enough for D177 to form a stable coordination with the moving $\mathrm{Ca}^{2+}$ ion. This spatial configuration suggests that the two sites are separated by a low energy barrier. The differences of negative charge between D178 and the carbonyls of T175 and the differences in the geometry of their interactions with $\mathrm{Ca}^{2+}$ provide a plausible explanation for the higher $\mathrm{Ca}^{2+}$ binding affinity at Site 1 than Site 3.

\section{Ion permeation mechanism}

The three $\mathrm{Ca}^{2+}$-binding sites in the selectivity filter of ${ }^{176}{ }_{\mathrm{LDDWSN}}{ }^{181}$ are separated by a distance of about $4.5 \AA$, which would result in substantial electrostatic repulsive interactions between bound ions. As in the case of the KcsA channel ${ }^{22}$, it is energetically unfavorable for $\mathrm{Ca}^{2+}$ ions to occupy adjacent sites simultaneously. This leads directly to our hypothesis of two interchangeable functional states of the selectivity filter in the crystal structure (Fig. 4a, 
b). In State $1, \mathrm{Ca}^{2+}$ ions occupy Site 1 and Site 3 . In State 2 , a single $\mathrm{Ca}^{2+}$ ion occupies Site 2. These two states might be further coupled with one of the two $\mathrm{Ca}^{2+}$ ions at the outer vestibule ready to enter the pore (Fig. 4c). The transition between these two states occurs either when $\mathrm{Ca}^{2+}$ jumps from position 1 or 3 to position 2 or a third ion enters on one side of the filter, causing an ion to move into position 2. It is likely that our crystal structures reflect a mixed population of $\mathrm{Ca}_{V} \mathrm{Ab}$ molecules in which only Site 2 is occupied by $\mathrm{Ca}^{2+}$ plus $\mathrm{Ca}_{\mathrm{V}} \mathrm{Ab}$ molecules in which Site 1 and/or Site 3 are occupied. Because of the high concentration of $\mathrm{Ca}^{2+}$ in the extracellular solution, $\mathrm{Ca}^{2+}$ will prefer to enter Site 1 and the weak binding of $\mathrm{Ca}^{2+}$ to Site 3 will force loss of $\mathrm{Ca}^{2+}$ into the low $\mathrm{Ca}^{2+}$ concentration in the cytosol. This generates a unidirectional flux of $\mathrm{Ca}^{2+}$ into the cell (Fig. 4c). The three-ion occupied state would be manifest only when the external $\mathrm{Ca}^{2+}$ concentration is increased enough that the flux reaches a limiting value ${ }^{3}$. The presence of the lower affinity Site 3 flanking the central cavity would further accelerate the flux of ions by allowing stepwise binding with relatively low chemical potential energy barriers ${ }^{7}$. The combination of ionic repulsion between $\mathrm{Ca}^{2+}$ ions bound at these sites and their stepwise change in binding affinity work together to allow rapid conductance in spite of the intrinsic high affinity for $\mathrm{Ca}^{2+}$ binding.

The mechanism underlying the dramatic difference in selectivity for $\mathrm{Ca}^{2+}$ over $\mathrm{Na}^{+}$in $\mathrm{Ca}_{\mathrm{V}} \mathrm{Ab}$ versus $\mathrm{Na}_{\mathrm{V}} \mathrm{Ab}$ is different from the mechanisms responsible for selectivity of $\mathrm{K}^{+}$ over $\mathrm{Na}^{+}$and for $\mathrm{Ca}^{2+}$ block revealed by high-resolution structural studies of the $\mathrm{NaK}$ channel (Supplementary Discussion) ${ }^{23-25}$. Biophysical modeling of $\mathrm{Ca}^{2+}$ permeation in vertebrate $\mathrm{Ca}_{V}$ channels has led to multiple proposed mechanisms, most of which involve two or more $\mathrm{Ca}^{2+}$ binding sites, yet only a single high affinity site that is required for both permeation and $\mathrm{Ca}^{2+}$ block was identified by mutagenesis and physiological analyses ${ }^{1}$. Our results with $\mathrm{Ca}_{\mathrm{V}} \mathrm{Ab}$ channels resolve this apparent discrepancy by showing that multiple $\mathrm{Ca}^{2+}$ binding sites are necessary for permeation, but only Site 2 binds divalent cations with sufficient affinity for block. Our results indicate that $\mathrm{Ca}^{2+}$ is conducted as a hydrated cation (Supplementary Discussion and Supplementary Fig. 5), consistent with the large estimated functional diameter of vertebrate $\mathrm{Ca}_{\mathrm{V}}$ channels of $6 \AA^{26}$. Detailed structure-function studies of vertebrate $\mathrm{Ca}_{V}$ channels show that mutations of the four residues equivalent to E177 have distinct effects on $\mathrm{Ca}^{2+}$ conductance and block, implying that domain-specific interactions with $\mathrm{Ca}^{2+}$ have evolved in vertebrate four-domain $\mathrm{Ca}_{\mathrm{V}}$ channels ${ }^{10,11,27-29}$. Vertebrate $\mathrm{Ca}_{\mathrm{V}}$ channels might share similar molecular mechanisms for $\mathrm{Ca}^{2+}$ permeation and selectivity despite their pseudosymmetric four-domain configuration.

\section{METHODS}

\section{Protein expression and purification}

The pFastBac-FLAG-Nav $\mathrm{Ab}$ (I217C) was used as the genetic background for $\mathrm{Ca}_{\mathrm{V}} \mathrm{Ab}$ constructs was previously described ${ }^{15,16}$. $\mathrm{Ca}_{\mathrm{V}} \mathrm{Ab}$ and its derivatives, ${ }^{175}$ TLDDWS $\underline{N}^{181},{ }^{175}$ TLEDWSD $^{181},{ }^{175}$ TLEDWSM $^{181}$, and ${ }^{175}$ TLDSWSM $^{181}$ were generated via site-directed mutagenesis using QuickChange (Stratagene). Recombinant baculovirus were produced using the Bac-to-Bac system (Invitrogen), and T. $n i$ insect cell were infected for large-scale protein purification. Cells were harvest $72 \mathrm{~h}$ post-infection and 
re-suspended in $50 \mathrm{mM}$ Tris- $\mathrm{HCl} \mathrm{pH}=8.0,200 \mathrm{mM} \mathrm{NaCl}$ (Buffer A) supplemented with protease inhibitors and DNase. After sonication, digitonin (EMD Biosciences) was added to $1 \%$ and solubilization was carried out for $1-2 \mathrm{~h}$ at $4^{\circ} \mathrm{C}$. Clarified supernatant was then incubated with anti-Flag M2-agarose resin (Sigma) for $1-2 \mathrm{~h}$ at $4{ }^{\circ} \mathrm{C}$ with gentle mixing. Flag-resin was washed with ten column volumes of buffer B (buffer A supplemented with $0.12 \%$ digitonin) and eluted with buffer B supplemented with $0.1 \mathrm{mg} / \mathrm{ml}$ Flag peptide. The eluent was concentrated and then passed over a Superdex 200 column (GE Healthcare) in 10 $\mathrm{mM}$ Tris- $\mathrm{HCl} \mathrm{pH}=8.0,100 \mathrm{mM} \mathrm{NaCl}$ and $0.12 \%$ digitonin. The peak fractions were concentrated using a Vivaspin $30 \mathrm{~K}$ centrifugal device.

\section{Crystallization and data collection}

$\mathrm{Ca}_{\mathrm{V}} \mathrm{Ab}$ and its derivatives were concentrated to $\sim 20 \mathrm{mg} \mathrm{ml}^{-1}$ and reconstituted into DMPC:CHAPSO (Anatrace) bicelles according to standard protocols ${ }^{30,31}$. The proteinbicelle preparation and a well solution containing 1.8-2.0 M ammonium sulfate, $100 \mathrm{mM}$ $\mathrm{Na}$-citrate $\mathrm{pH}=5.0$ was mixed with a 1:1 ratio and set up in a hanging-drop vapour-diffusion format. The $\mathrm{Ca}^{2+}$ - derivative crystals were obtained by soaking $\mathrm{Ca}_{V} \mathrm{Ab}$ and other mutant crystals in a cryo-protection solution (0.1M Na-acetate $\mathrm{pH}=5.0,26 \%$ glucose and $2.0 \mathrm{M}$ ammonium sulfate) containing the indicated concentrations of $\mathrm{Ca}^{2+}$ for $40-60 \mathrm{~min}$ at $4{ }^{\circ} \mathrm{C}$. The $\mathrm{Cd}^{2+}$ and $\mathrm{Mn}^{2+}$ derivatives were obtained by soaking $\mathrm{Ca}_{V} \mathrm{Ab}$ in the presence of 100 $\mathrm{mM} \mathrm{Cd}{ }^{2+}$ or $\mathrm{Mn}^{2+}$, respectively. Crystals were then plunged into liquid nitrogen and maintained at $100 \mathrm{~K}$ during all data collection procedures.

All anomalous diffraction datasets were collected at $1.75 \AA$ with the same synchrotron radiation source (Advanced Light Source, BL8.2.1). To optimize the anomalous signal, the datasets were collected by using the "inverse beam strategy" with the wedge size of $5^{\circ}$.

\section{Structure determination, refinement, and analyses}

X-ray diffraction data were integrated and scaled with the HKL2000 package ${ }^{32}$ and further processed with the CCP4 package ${ }^{33}$. The structure of $\mathrm{Ca}_{V} \mathrm{Ab}$ and its derivatives were solved by molecular replacement by using an individual subunit of the $\mathrm{Na}$ Ab structure (PDB code $3 \mathrm{RVY}$ ) as the search template. The datasets were processed in $\mathrm{C} 2$ space group and there are four molecules in one asymmetric unit. We choose the I222 space group to process the datasets for initial structural determination, but we found that the bound ions are slightly offcenter with respect to the axis of the pore. Therefore, to better interpret the coordination of $\mathrm{Ca}^{2+}, \mathrm{Cd}^{2+}$, and $\mathrm{Mn}^{2+}$, we solved the structures in the $\mathrm{C} 2$ space group. Crystallography and NMR System software ${ }^{34}$ was used for refinement of coordinates and $B$-factors. Final models were obtained after several cycles of refinement with REFMAC ${ }^{35}$ and PHENIX ${ }^{36}$ and manual re-building using program $\mathrm{COOT}^{37}$. The geometries of the final structural models of $\mathrm{Ca}_{\mathrm{V}} \mathrm{Ab}$ and its derivatives were verified using PROCHECK ${ }^{38}$. The divalent cations were identified by anomalous difference Fourier maps calculated using data collected at wavelengths of $1.75 \AA$ for $\mathrm{Ca}^{2+}, \mathrm{Cd}^{2+}$ and $\mathrm{Mn}^{2+}$. Detailed crystallographic data and refinement statics for all the constructs are shown in Table S1. All structural figures were prepared with the PyMol software ${ }^{39}$. 


\section{Electrophysiology}

NavAb-WT expressed by infection of insect cells (High5) activates at very negative potentials V1/2 -98 mV) and shows a strong, late use-dependent phase of slow inactivation. Mutation N49K shifts the activation curve $\sim 75 \mathrm{mV}$ to more positive potentials and abolishes the use-dependent inactivation ${ }^{40}$. All NavAb/CavAb constructs used were made on the background of $\mathrm{N} 49 \mathrm{~K}$ mutation and showed good expression, allowing measurement of ionic currents $24-48 \mathrm{~h}$ post-infection.

Whole-cell currents were recorded using an Axopatch 200 amplifier (Molecular Devices, Sunnyvale, CA) with glass micropipettes (2-5 M 2 ). Capacitance was subtracted and 80$90 \%$ of series resistance was compensated using internal amplifier circuitry. For reversal potential measurements, the intracellular pipette solution contained (in $\mathrm{mM}$ ): $100 \mathrm{NaF}, 10$ $\mathrm{NaCl}, 20$ HEPES-Na, 10 EGTA, pH 7.4 (adjusted with $\mathrm{NaOH},\left[\mathrm{Na}^{+}\right]_{\text {Total }}=146 \mathrm{mM}$ ). Extracellular solution contained in $(\mathrm{mM}) 10 \mathrm{CaCl}_{2}, 140$ NMDG-methanesulfonate, 20 HEPES, (pH 7.4, adjusted with $\left.\mathrm{Ca}(\mathrm{OH})_{2},\left[\mathrm{Ca}^{2+}\right]_{\text {Total }}=12 \mathrm{mM}\right)$. For Ba ${ }^{2+}$ reversal potential measurements, $\mathrm{BaCl}_{2}$ replaced $\mathrm{CaCl}_{2}$. Current-voltage (I-V) relationships were recorded in response to steps to voltages ranging from -100 to $+70 \mathrm{mV}$ in 5 or $10 \mathrm{mV}$ increments from a holding potential of $-100 \mathrm{mV}$. Pulses were generated and currents were recorded using Pulse software controlling an Instrutech ITC18 interface (HEKA, Great Neck, NY). Data were analyzed using Igor Pro 6.2 (WaveMetrics, Lake Oswego, OR). Sample sizes were chosen to give SEM values of less than $10 \%$ of peak values based on prior experimental experience.

Relative permeability values were calculated as described ${ }^{41}$. The permeability ratio was calculated as:

$$
P_{x} / P_{N a}=a_{N a}\left[\exp \left(\frac{E_{r e v} F}{R T}\right)\right]\left[\exp \left(\frac{E_{r e v} F}{R T}\right)+1\right] / 4 a_{x}
$$

where F, R, T, and Erev are Faraday constant, gas constant, absolute temperature, and reversal potential, respectively. $a_{x}$, denotes the activity of the external divalent ion, $x,\left(\mathrm{Ca}^{2+}\right.$ or $\left.\mathrm{Ba}^{2+}\right)$ and $a_{\mathrm{Na}}$, the activity of intracellular sodium. The calculated activity coefficients were $\gamma_{\mathrm{Ca}}=0.33, \gamma_{\mathrm{Ba}}=0.30, \gamma_{\mathrm{Na}}=0.74$. All potentials were corrected for the experimentally determined liquid junction potential.

For anomalous mole fraction and blocking experiments, the divalent $\left(\mathrm{Ca}^{2+}, \mathrm{Cd}^{2+}\right.$, and $\left.\mathrm{Mn}^{2+}\right)$ was diluted in $10 \mathrm{mM} \mathrm{BaCl}_{2}, 140 \mathrm{mM}$ NMDG-methanesulfonate, and $10 \mathrm{mM}$ HEPES and perfused for 2-3 min before recording a current-voltage curve. The peak value of the I-V curve was measured and normalized to the peak value without the divalent cation.

\section{Supplementary Material}

Refer to Web version on PubMed Central for supplementary material. 


\section{Acknowledgments}

We are grateful to the beamline staff at the Advanced Light Source (BL8.2.1 and BL8.2.2) for their assistance during data collection. Research reported in this publication was supported by the National Institute of Neurological Disorders and Stroke (NINDS) of the National Institutes of Health under award number R01NS015751 (W.A.C.), the National Heart, Lung, and Blood Institute (NHLBI) of the National Institutes of Health under award number R01HL112808 (W.A.C. and N.Z.), and a National Research Service Award from training grant T32GM008268 (T.M.H.). The content is solely the responsibility of the authors and does not necessarily represent the official views of the National Institutes of Health. This work was also supported by the Howard Hughes Medical Institute (N. Z.).

\section{References}

1. Sather WA, McCleskey EW. Permeation and selectivity in calcium channels. Annu Rev Physiol. 2003; 65:133-159. [PubMed: 12471162]

2. Catterall WA. Voltage-gated calcium channels. Cold Spring Harb Perspect Biol. 2011; 3:a003947. [PubMed: 21746798]

3. Almers W, McCleskey EW. Non-selective conductance in calcium channels of frog muscle: calcium selectivity in a single-file pore. J Physiol. 1984; 353:585-608. [PubMed: 6090646]

4. Almers W, McCleskey EW, Palade PT. A non-selective cation conductance in frog muscle membrane blocked by micromolar external calcium ions. J Physiol. 1984; 353:565-583. [PubMed: 6090645]

5. Hess P, Tsien RW. Mechanism of ion permeation through calcium channels. Nature. 1984; 309:453-456. [PubMed: 6328315]

6. Armstrong CM, Neyton J. Ion permeation through calcium channels. A one-site model. Ann N Y Acad Sci. 1991; 635:18-25. [PubMed: 1660235]

7. Dang TX, McCleskey EW. Ion channel selectivity through stepwise changes in binding affinity. J Gen Physiol. 1998; 111:185-193. [PubMed: 9450938]

8. Lopin KV, Obejero-Paz CA, Jones SW. Evaluation of a two-site, three-barrier model for permeation in $\mathrm{Ca}(\mathrm{V}) 3.1$ (alpha1G) T-type calcium channels: $\mathrm{Ca}^{2+}, \mathrm{Ba}^{2+}, \mathrm{Mg}^{2+}$, and $\mathrm{Na}^{+} \mathrm{J}$ Membr Biol. 2010; 235:131-143. [PubMed: 20512318]

9. Heinemann SH, Terlau H, Stuhmer W, Imoto K, Numa S. Calcium channel characteristics conferred on the sodium channel by single mutations. Nature. 1992; 356:441-443. [PubMed: 1313551]

10. Ellinor PT, Yang J, Sather WA, Zhang JF, Tsien RW. Ca ${ }^{2+}$ channel selectivity at a single locus for high-affinity $\mathrm{Ca}^{2+}$ interactions. Neuron. 1995; 15:1121-1132. [PubMed: 7576655]

11. Yang J, Ellinor PT, Sather WA, Zhang JF, Tsien RW. Molecular determinants of $\mathrm{Ca}^{2+}$ selectivity and ion permeation in L-type $\mathrm{Ca}^{2+}$ channels. Nature. 1993; 366:158-161. [PubMed: 8232554]

12. Kim MS, Morii T, Sun LX, Imoto K, Mori Y. Structural determinants of ion selectivity in brain calcium channel. FEBS Lett. 1993; 318:145-148. [PubMed: 8382625]

13. Cibulsky SM, Sather WA. The EEEE locus is the sole high-affinity $\mathrm{Ca}^{2+}$ binding structure in the pore of a voltage-gated $\mathrm{Ca}^{2+}$ channel: block by $\mathrm{Ca}^{2+}$ entering from the intracellular pore entrance. J Gen Physiol. 2000; 116:349-362. [PubMed: 10962013]

14. Cloues RK, Cibulsky SM, Sather WA. Ion interactions in the high-affinity binding locus of a voltage-gated $\mathrm{Ca}^{2+}$ channel. J Gen Physiol. 2000; 116:569-586. [PubMed: 11004206]

15. Payandeh J, Scheuer T, Zheng N, Catterall WA. The crystal structure of a voltage-gated sodium channel. Nature. 2011; 475:353-358. [PubMed: 21743477]

16. Payandeh J, Gamal El-Din TM, Scheuer T, Zheng N, Catterall WA. Crystal structure of a voltagegated sodium channel in two potentially inactivated states. Nature. 2012; 486:135-139. [PubMed: 22678296]

17. Zhang X, et al. Crystal structure of an orthologue of the NaChBac voltage-gated sodium channel. Nature. 2012; 486:130-134. [PubMed: 22678295]

18. Ren D, et al. A prokaryotic voltage-gated sodium channel. Science. 2001; 294:2372-2375. [PubMed: 11743207]

19. Yu FH, Catterall WA. The VGL-chanome: a protein superfamily specialized for electrical signaling and ionic homeostasis. Sci STKE. 2004; 2004:re15. [PubMed: 15467096] 
20. Koishi R, et al. A superfamily of voltage-gated sodium channels in bacteria. J Biol Chem. 2004; 279:9532-9538. [PubMed: 14665618]

21. Yue L, Navarro B, Ren D, Ramos A, Clapham DE. The cation selectivity filter of the bacterial sodium channel, NaChBac. J Gen Physiol. 2002; 120:845-853. [PubMed: 12451053]

22. Morais-Cabral JH, Zhou Y, MacKinnon R. Energetic optimization of ion conduction rate by the K ${ }^{+}$selectivity filter. Nature. 2001; 414:37-42. [PubMed: 11689935]

23. Alam A, Jiang Y. Structural analysis of ion selectivity in the NaK channel. Nat Struct Mol Biol. 2009; 16:35-41. [PubMed: 19098915]

24. Alam A, Shi N, Jiang Y. Structural insight into $\mathrm{Ca}^{2+}$ specificity in tetrameric cation channels. Proc Natl Acad Sci U S A. 2007; 104:15334-15339. [PubMed: 17878296]

25. Derebe MG, et al. Tuning the ion selectivity of tetrameric cation channels by changing the number of ion binding sites. Proc Natl Acad Sci U S A. 2011; 108:598-602. [PubMed: 21187421]

26. McCleskey EW, Almers W. The Ca channel in skeletal muscle is a large pore. Proc Natl Acad Sci U S A. 1985; 82:7149-7153. [PubMed: 2413461]

27. Chen XH, Tsien RW. Aspartate substitutions establish the concerted action of P-region glutamates in repeats I and III in forming the protonation site of L-type $\mathrm{Ca}^{2+}$ channels. J Biol Chem. 1997; 272:30002-30008. [PubMed: 9374474]

28. Cibulsky SM, Sather WA. Control of ion conduction in L-type $\mathrm{Ca}^{2+}$ channels by the concerted action of S5-6 regions. Biophys J. 2003; 84:1709-1719. [PubMed: 12609873]

29. Williamson AV, Sather WA. Nonglutamate pore residues in ion selection and conduction in voltage-gated $\mathrm{Ca}^{2+}$ channels. Biophys J. 1999; 77:2575-2589. [PubMed: 10545358]

30. Faham S, Bowie JU. Bicelle crystallization: a new method for crystallizing membrane proteins yields a monomeric bacteriorhodopsin structure. J Mol Biol. 2002; 316:1-6. [PubMed: 11829498]

31. Faham S, Boulting GL, Massey EA, Yohannan S, Yang D, Bowie JU. Crystallization of bacteriorhodopsin from bicelle formulations at room temperature. Protein Sci. 2005; 14:836-840. [PubMed: 15689517]

32. Otwinowski Z, Minor W. Processing of X-ray diffraction data collected in oscillation mode. Meth Enzymol. 1997; 276:307-326.

33. ccp4. The CCP4 suite: programs for protein crystallography. Acta crystallographica Section D, Biological crystallography. 1994; 50:760-763.

34. Brunger AT, Adams PD, Clore GM, DeLano WL, Gros P, Grosse-Kunstleve RW, Jiang JS, Kuszewski J, Nilges M, Pannu NS, Read RJ, Rice LM, Simonson T, Warren GL. Crystallography \& NMR system: A new software suite for macromolecular structure determination. Acta crystallographica Section D, Biological Crystallography. 1998; 54:905-921.

35. Murshudov GN, Vagin AA, Dodson EJ. Refinement of macromolecular structures by the maximum-likelihood method. Acta crystallographica Section D, Biological crystallography. 1997; 53:240-255.

36. Adams PD, Afonine PV, Bunkoczi G, Chen VB, Davis IW, Echols N, Headd JJ, Hung LW, Kapral GJ, Grosse-Kunstleve RW, McCoy AJ, Moriarty NW, Oeffner R, Read RJ, Richardson DC, Richardson JS, Terwilliger TC, Zwart PH. PHENIX: a comprehensive Python-based system for macromolecular structure solution. Acta crystallographica Section D, Biological crystallography. 2010; 66:213-221.

37. Emsley P, Cowtan K. Coot: model-building tools for molecular graphics. Acta crystallographica Section D, Biological crystallography. 2004; 60:2126-2132.

38. Laskowski RA, Moss DS, Thornton JM. Main-chain bond lengths and bond angles in protein structures. J Mol Biol. 1993; 231:1049-1067. [PubMed: 8515464]

39. DeLano, WL. PyMOL molecular viewer(V12r3pre). 2002. (http://www.pymol.org)

40. Gamal El-Din TM, Martinez GQ, Payandeh J, Scheuer T, Catterall WA. A gating charge intereaaction required for late slow inactivation of the bacterial sodium channel NavAb. J Gen Physiol. 2013; 142:181-190. [PubMed: 23980192]

41. Yue L, Navarro B, Ren D, Ramos A, Clapham DE. The cation selectivity filter of the bacterial sodium channel, NaChBac. J Gen Physiol. 2002; 120:845-853. [PubMed: 12451053] 


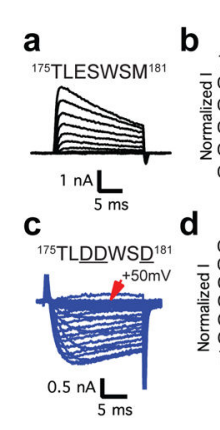

h
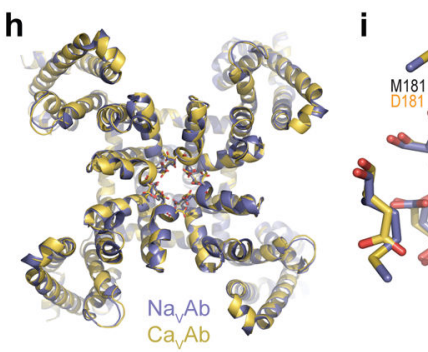

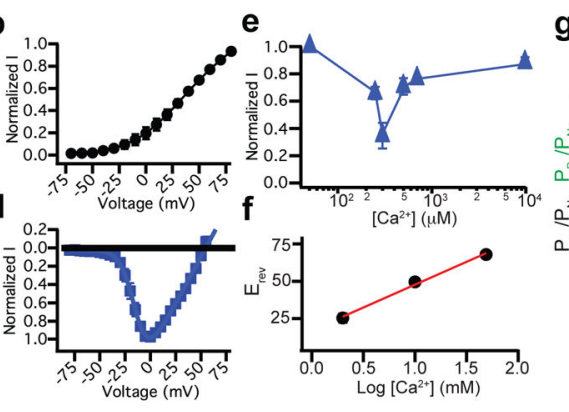

j
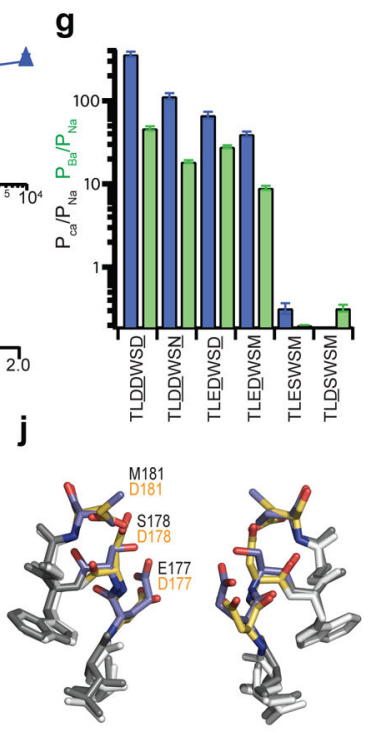

Figure 1. Structure and function of the CavAb channel

a, b, Outward $\mathrm{Na}^{+}$current conducted by $\mathrm{Na}$ Ab with $10 \mathrm{mM}$ extracellular $\mathrm{Ca}^{2+}$ and 140 $\mathrm{mM}$ intracellular $\mathrm{Na}^{+}$. Holding potential, $-100 \mathrm{mV}$; 20-ms, 10-mV step depolarizations. c, d, Voltage-dependent conductance of inward $\mathrm{Ca}^{2+}$ current by $\mathrm{Ca}_{\mathrm{V}} \mathrm{Ab}$ under the same conditions. 20-ms, 5-mV step depolarizations. e, Biphasic anomalous mole fraction effect of increasing $\mathrm{Ca}^{2+}$ as indicated, with $\mathrm{Ba}^{2+}$ as the balancing divalent cation: $10 \mathrm{mM} \mathrm{Ba}^{2+}$ with 0 to $0.5 \mathrm{mM} \mathrm{Ca}^{2+}$, $9.3 \mathrm{mM} \mathrm{Ba}^{2+}$ with $0.7 \mathrm{mM} \mathrm{Ca}^{2+}$, and $0 \mathrm{mM} \mathrm{Ba}^{2+}$ with $10 \mathrm{mM} \mathrm{Ca}^{2+}(\mathrm{n}=$ 4-10). f. Reversal potential ( $\mathrm{E}_{\mathrm{rev}}$ ) versus $\mathrm{Ca}^{2+}$ concentration. $\mathrm{g}$, Relative permeability of $\mathrm{Ca}_{\mathrm{V}} \mathrm{Ab}$ and its derivatives as measured from bi-ionic reversal potentials. $\mathrm{P}_{\mathrm{Ca}} / \mathrm{P}_{\mathrm{Na}}$, blue; $\mathrm{P}_{\mathrm{Ba}} / \mathrm{P}_{\mathrm{Na}}$, green $(\mathrm{n}=5-22) . \mathbf{h}$, Cartoon representation of the overall structure of $\mathrm{Ca}_{\mathrm{V}} \mathrm{Ab}$ (yellow) superimposed with $\mathrm{Na}_{V} \mathrm{Ab}$ (slate). $\mathbf{i}, \mathbf{j}$, Top and side views of the superimposed selectivity filters of $\mathrm{Ca}_{\mathrm{V}} \mathrm{Ab}$ (yellow) and $\mathrm{Na}_{\mathrm{V}} \mathrm{Ab}$ (slate) in stick representation. The three original $\mathrm{NavAb}$ residues (black) and substituted $\mathrm{CavAb}$ residues (orange) are indicated. Errors bars in $\mathbf{a}-\mathbf{g}$ are standard error of the mean. 
a

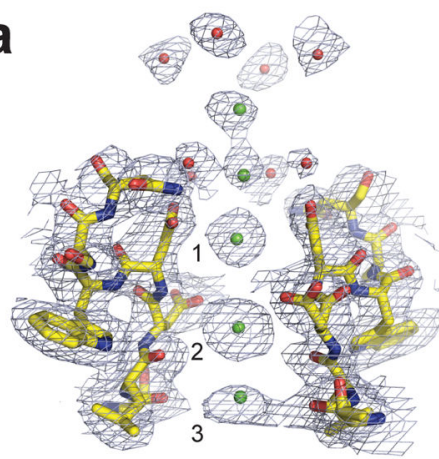

C

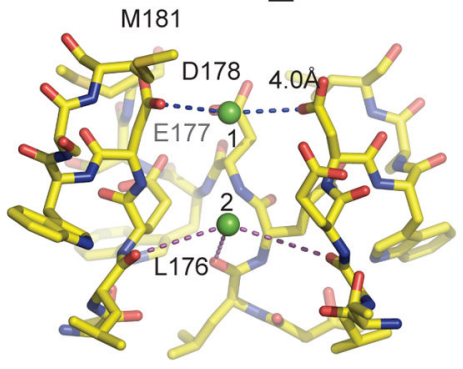

e

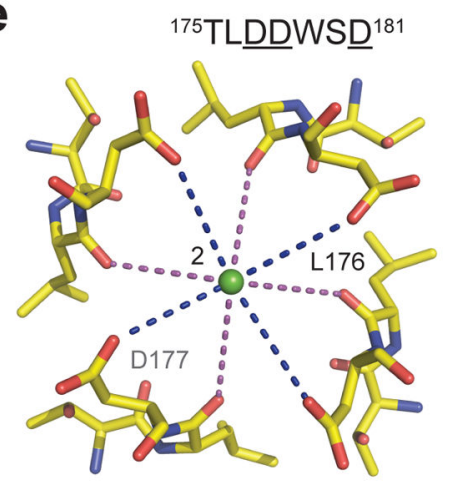

b

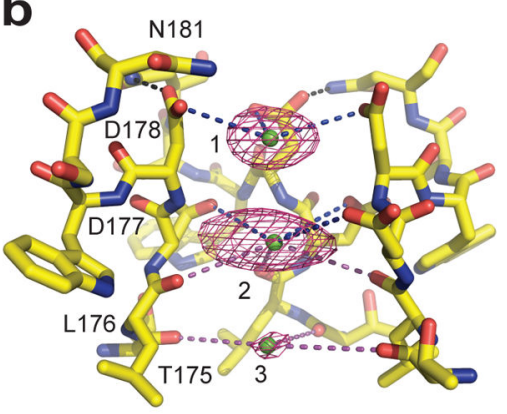

d
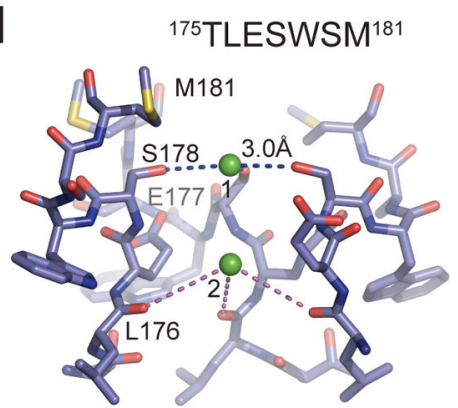

f

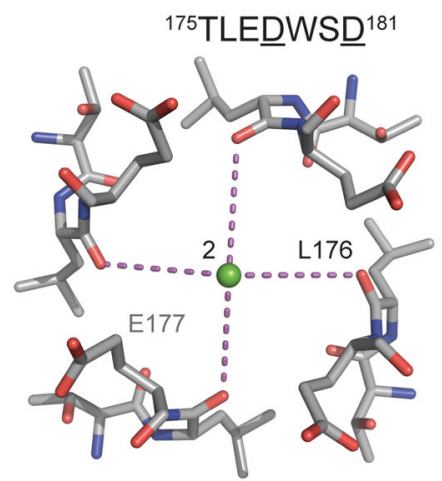

Figure 2. $\mathrm{Ca}^{2+}$ binding sites in and near the selectivity filter of $\mathrm{Nav}_{\mathrm{V}} \mathrm{Ab}, \mathrm{Ca} \mathrm{Ab}$, and their derivatives

a, Electron density at the selectivity filter of ${ }^{175}$ TLDDWSN ${ }^{181}$ (also see Supplementary Fig. 4). The $2 F_{o}-F_{c}$ electron density map (contoured at $2 \sigma$ ) of select residues in the selectivity filter with two diagonally opposed subunits shown in sticks, the $\mathrm{Ca}^{2+}$ ions along the ion pathway in green spheres and water molecules in red spheres. $\mathbf{b}$, Densities at $\mathrm{Ca}^{2+}$ binding Site 1 and 2 from the anomalous difference Fourier map $(3 \sigma)$ calculated from the diffraction data of a ${ }^{175}$ TLDDWSN ${ }^{181}$ mutant crystal soaked in the presence of $5 \mathrm{mM} \mathrm{Ca}^{2+}$ and collected at $1.75 \AA$ wavelength. The distances between $\mathrm{Ca}^{2+}$ and oxygen atoms (dashed lines) are about $4.0 \AA$ at Site 1 (blue lines), $4.4 \AA$ at Site 2 (blue and magenta lines), and 5.0 $\AA$ (magenta line) at Site 3. For clarity, the subunit closest to the viewer is not shown. c, d, A comparison between ${ }^{175}$ TLEDWSM ${ }^{181}$ and ${ }^{175}$ TLESWSM $^{181}$ (NavAb) highlighting the importance of Site 1 for $\mathrm{Ca}^{2+}$ selectivity. e, f, A comparison between ${ }^{175} \mathrm{TLDDWSD}^{181}$ $(\mathrm{Ca} V \mathrm{Ab})$ and ${ }^{175}{ }^{\mathrm{TLEDWWS}} \underline{\mathrm{D}}^{181}$ highlighting the role of Site 2 in fine tuning $\mathrm{Ca}^{2+}$ selectivity. All structures were determined in the presence of $15 \mathrm{mM} \mathrm{Ca}^{2+}$. 

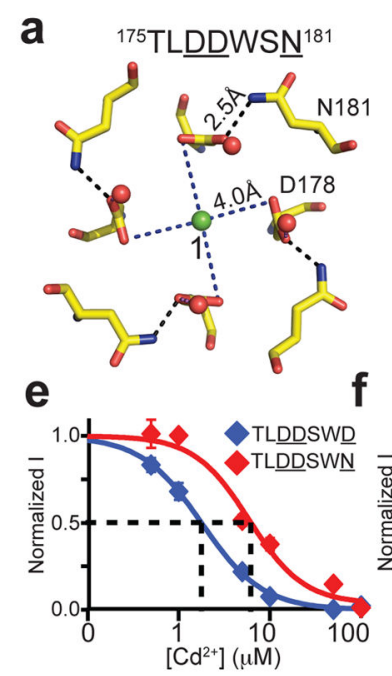

b ${ }^{175} T L D D W S \underline{D}^{181}$

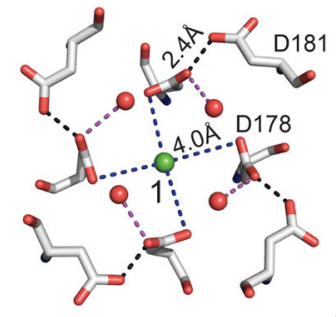

(1)

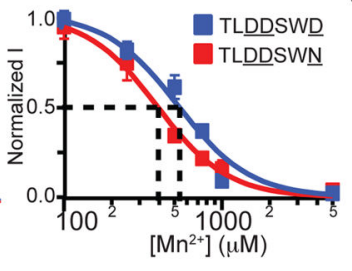

C ${ }^{175}$ TLDDWSM $^{181}$

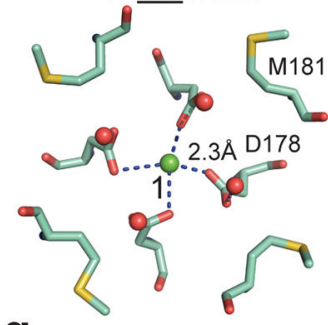

g

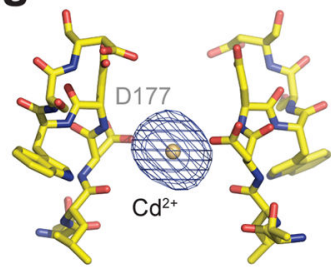

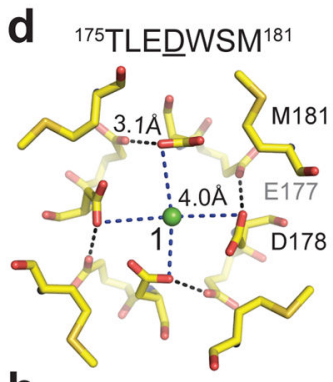

h

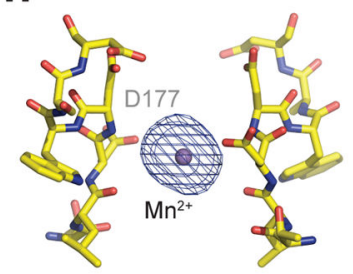

Figure 3. Ion binding and block of $\mathrm{Ca} \mathrm{Ab}$ and its derivatives

$\mathbf{a}, \mathbf{b}$, Top view of Site 1 with a hydrated $\mathrm{Ca}^{2+}$ ion coordinated by D178 with the help of N181 and D181 in ${ }^{175} \mathrm{TLDDWS}^{181}$ and ${ }^{175} \mathrm{TLDDWSD}^{181}$ (Cav $\left.\mathrm{Ab}\right)$, respectively. c, Binding of a dehydrated $\mathrm{Ca}^{2+}$ ion at Site 1 in the nonconductive ${ }^{175}$ TLDDWSM $^{181}$ mutant. d, Coordination of a hydrated $\mathrm{Ca}^{2+}$ ion at the Site 1 of the ${ }^{175}$ TLEDWSM $^{181}$ mutant. Despite the absence of a polar residue at amino acid 181, E177 in ${ }^{175}$ TLEDWSM $^{181}$ is able to hold D178 in place to allow the binding of a hydrated $\mathrm{Ca}^{2+}$ ion. e, f, Block of $\mathrm{Ca}^{2+}$ conductance by the indicated concentrations of $\mathrm{Cd}^{2+}$ and $\mathrm{Mn}^{2+} \cdot{ }^{175} \mathrm{TLDDWSD}^{181}$ : $\mathrm{IC}_{50}\left(\mathrm{Cd}^{2+}\right), 1.7 \pm 0.04 \mu \mathrm{M} ; \mathrm{IC}_{50}\left(\mathrm{Mn}^{2+}, 526 \pm 22 \mu \mathrm{M} .{ }^{175} \mathrm{TLDDWSN}^{181}: \mathrm{IC}_{50}\left(\mathrm{Cd}^{2+}\right), 5.9 \pm 0.4\right.$ $\mu \mathrm{M} ; \mathrm{IC}_{50}\left(\mathrm{Mn}^{2+}\right), 388 \pm 7 \mu \mathrm{M}$. Error bars are standard error of the mean. $\mathbf{g}, \mathbf{h}$, Side view of the $\mathrm{Cd}^{2+}$ and $\mathrm{Mn}^{2+}$ binding sites in the selectivity filter of $\mathrm{Ca}_{V} \mathrm{Ab}$. The anomalous difference Fourier map densities (blue mesh, contoured at $5 \sigma$ ) of the bound blocking ions are calculated using diffraction data collected at $1.75 \AA$ wavelength. For clarity, the residues forms the selectivity filter of the closest subunit to the viewer is removed. 
a

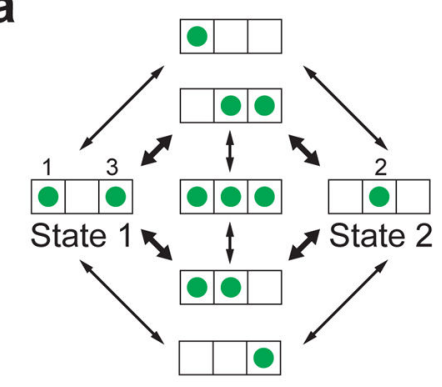

C

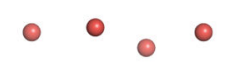

(

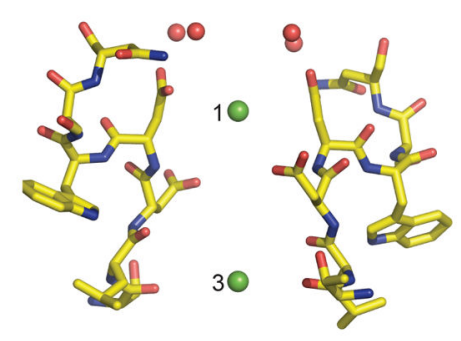

b
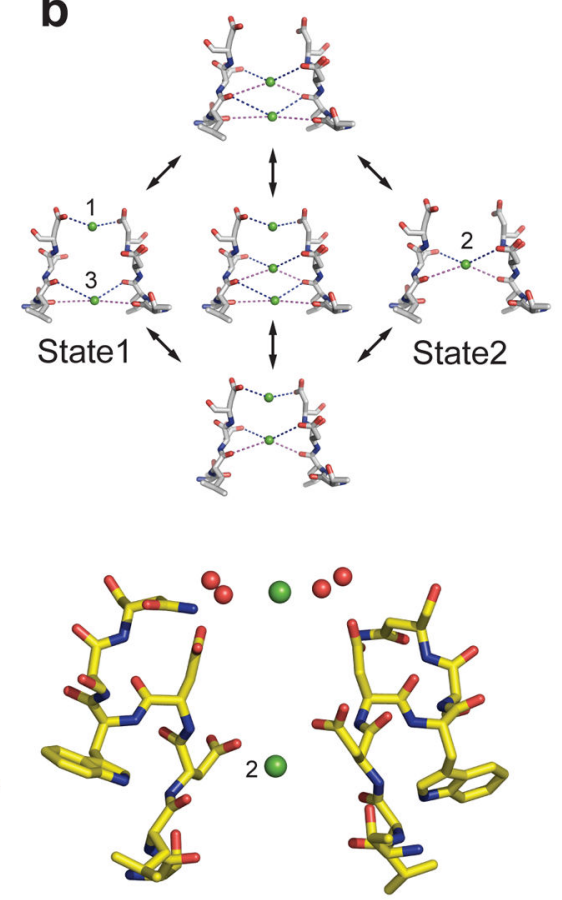

Figure 4. Catalytic cycle for $\mathrm{Ca}^{2+}$ conductance by $\mathrm{CavAb}$

a, An ionic occupancy state diagram of $\mathrm{Ca}_{\mathrm{V}} \mathrm{Ab}$ showing two proposed low energy states and the potential transitions that connect them. Each state of the selectivity filter is represented by a three-box rectangle with Sites $1-3$ going from left to right. Green circles represent $\mathrm{Ca}^{2+}$ ions. Note that transitions in the inner circle potentially lead to ion repulsion, which might facilitate conduction. These transitions in the inner circle are more probable than those in the outer circle, as denoted by the bold arrows. b, The structural basis of the ionic occupancy states depicted in the inner circle of the state diagram shown on the left. The clockwise cycle represents a path for inward flux of $\mathrm{Ca}^{2+}$ ions through the selectivity filter. c, Coupling of extracellular $\mathrm{Ca}^{2+}$ binding sites and the three sites within the selectivity filter in the two proposed ionic occupancy states. When two $\mathrm{Ca}^{2+}$ ions bind to position 1 and 3 in the filter, the entryway $\mathrm{Ca}^{2+}$ ion is placed furthest from the pore (left). When one $\mathrm{Ca}^{2+}$ ion binds to position 2 within the filter, the ion outside the filter is pulled closer to the pore (right). 